\title{
KOORDINATIIVSED PARTIKLID LAUSE PERIFEERIAS ${ }^{1}$
}

\author{
HELLE METSLANG, \\ KARL PAJUSALU, KÜLLI HABICHT
}

\begin{abstract}
Annotatsioon. Artiklis vaadeldakse rinnastussidenditest kujunenud partiklite või, ja ning aga kasutust lause vasakus ja paremas perifeerias (lause alguses ja lõpus), eristades järgmisi funktsioone: 1) teksti või vestluse organiseerimine: eelneva või järgneva tekstiga seostamine; 2) subjektiveerimine, 3) intersubjektiveerimine. Nii standardkeele kui ka murrete korpusematerjali analüüsist ilmneb, et kõik kolm funktsiooni on esindatud mõlemas perifeerias, kuid subjektiivsed ja intersubjektiivsed kasutused kujunevad ennekõike vasakus, hiljem ja piiratumalt ka paremas perifeerias. Mõlemas perifeerias vastab funktsiooninihete järjestus skaalale mittesubjektiivne $>$ subjektiivne $>$ intersubjektiivne. On märgata ka vasakus perifeerias kujunenud kasutuse nihkumist paremasse. Mehhanismideks on seejuures peamiselt tagasihaare ja sildkontekstid. Eesti keele vasakut perifeeriat esiletõstvas tendentsis võib oletada areaalset ilmingut, sest lausealgulised partiklid on omased Läänemere areaali keeltele.
\end{abstract}

Võtmesõnad: subjektiveerimine, intersubjektiveerimine, küsipartikkel, tagasihaare, eesti keel

\section{Sissejuhatuseks}

Lause äärtele, algusesse ja lõppu, paigutuvad sageli funktsioonisõnad, mille ülesandeks on mõjutada tervet lauset: anda lause sisule seos konteksti ja kõnesituatsiooniga, esitada hinnanguid lause sisu kohta, näidata lause funktsiooni suhtluses. Neis positsioonides, lause (resp . intonatsiooniüksuse, lausungi) põhisisu vormistavast osast välja jäävas perifeerias, suhestub lause eriti selgelt ümbritseva kontekstiga: pragmaatikast, tekstist ja vestlusest tulenevate teguritega. Eristatakse vasakut ja paremat perifeeriat (ingl left periphery, LP; right periphery, RP) - lause algus on

Uurimust on toetanud projekt „Kirjakeele morfosüntaksi varieerumise integreeritud mudel: pilootuuring eesti keele näitel" (PUT 475). 
vasakul, lõpp paremal. Perifeeriates paiknevad sõnad väljendavad sageli ka subjektiivseid või intersubjektiivseid tähendusi. Subjektiivsus seisneb kõneleja suhtumiste, hinnangute ja hoiakute väljendamises, hõlmates näiteks modaalsust ja emotiivsust; intersubjektiivsus seisneb suhestumises kuulaja või lugejaga, vestluspartneri kaasahaaramises näiteks kõneakti markeerimise kaudu. Keelevahendi funktsiooninihete suund kaldub olema mittesubjektiivne $>$ subjektiivne $>$ intersubjektiivne. (Traugott 2003; Valdmets, Habicht 2013: 210-211)

Perifeeriate tööjaotuse kohta on esitatud lause n-ö asümmeetrilisuse hüpotees, mille kohaselt vasakusse perifeeriasse kalduvad subjektiivseid, paremasse aga intersubjektiivseid tähendusi kandvad elemendid (Kate Beeching $\mathrm{jt}^{2}$ ). Järjest enamate keelte (peale inglise keele nt prantsuse, saksa, jaapani, korea keel) kaasamine arutellu on toonud nii poolt- kui ka vastunäiteid ja osutanud, et keeltel on perifeeriate funktsioonides ja nende dünaamikas nii ühis- kui ka erijooni ning et siingi toimivad areaalsed tendentsid. Toetudes senistes käsitlustes (vt nt Vaskó, Fretheim 1997; Haselow 2011; Traugott 2012; ka Sohn ${ }^{3}$ ) välja toodud partiklite funktsioonidele perifeeriates, jaotame need kolme rühma, mis on vastavuses ka eeltoodud tähendusmuutuste järjestusega mittesubjektiivne $>$ subjektiivne $>$ intersubjektiivne. Lisatud näited illustreerivad eesti keele rinnastavatel sidesõnadel põhinevate partiklite kasutust.

1) Teksti või vestluse organiseerimine konnektiivpartiklina: eelneva või järgneva tekstiga seostamine; jätku pakkumine eelnevale tekstile (näited 1,2), laiendus (viide rinnastatud elementide lisamise võimalusele (3)), kõnevooru alustamine, tagasihaare (varasema tekstiga seostamine, ingl afterthought) (4).

(1) Kristus oli üles tõusnud. Helistati kirikukelli. Aga see oli vist juba Fuschlis, kuhu olime jõudnud pärast pikka jalgsimatka mägedes. (ILU 1990)

2 Kate Beeching, Liesbeth Degand, Ulrich Detges, Elizabeth Closs Traugott, Richard Waltereit, Summary of the Workshop on Meaning in Diachrony at the Conference on Meaning in Interaction, University of the West of England, Bristol, April 23-25 2009.

3 Sung-Ock Sohn, The emergence and function of the left peripheral versus the right peripheral expressions in Korean: from a discourse marker to a final particle. Ettekanne 13. rahvusvahelisel pragmaatikakonverentsil New Delhis 10. septembril 2013. 
(2) Sosaar imiteerib kahekõnet: „Sa olid ka seal Lääne-Eesti Pangas? - Jah. Kes sa seal olid? - Juhatuse esimees. - Ja Kranich oli? - Haapsalu filiaali direktor. - Aaa, sinu alluv." (EE 1996)

(3) Läheks maale, teeks sauna ja...

(4) Kahetseb, et see kõik nii läks, sest laadiku-sugusele mehele on ta kindlasti vaid seniks-kuniks... Minule aga... (ILU 1970).

Teksti organiseerimisel tekkivaid tähendusseoseid ilmestab joonis 1 . Selle skeemidest esimene kujutab vasaku perifeeria seost eelneva kontekstiga, mille suhtes lause pakub alternatiivi, jätku või vastandust(1). Teine skeem kujutab parema perifeeria põhilist funktsiooni: vihjata poolelijäävale jätkamisele alternatiivi, lisanduse või vastandusega (3). Kolmas skeem näitlikustab tagasihaaret: seost eelneva kontekstiga, mida tavajuhul näidatakse vasakus perifeerias (nagu Aga minule...), markeerib partikkel paremas perifeerias (4).

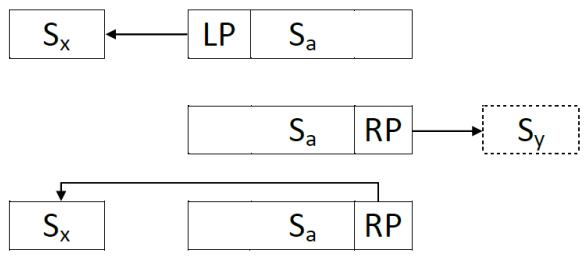

Joonis 1. Perifeeriate vahendatavad kontekstiseosed

$\left(\mathrm{S}_{\mathrm{a}}-\right.$ perifeeriaga lause; $\mathrm{S}_{\mathrm{x}}-$ eelnev kontekst;

$\mathrm{S}_{\mathrm{y}}$ - potentsiaalne järgnev kontekst; LP - vasak perifeeria;

$\mathrm{RP}$ - parem perifeeria)

2) Subjektiveerimine: modaalsed ja afektiivsed tähendused (5), jätkamisel viivitamine, kõhklemine (6), endale suunatud küsimused.

(5) Või ta seda isegi teab.

(6) „Mul oleks weel kirikherrale kõneleda, aga... aga...” (ILU 1900)

3) Intersubjektiveerimine: kuulajale suunatud küsimused (7), käsud, etteheited (8), vastuvaidlemised, kaasvestleja ütluste kommenteerimised, väljenduse pehmendamine jm viisakusvõtted.

(7) Ilm läheb külmaks või?

(8) Aga härra leitnant! (ILU 1930) 
Siinses kirjutises võtame vaatluse alla kolm sõna, mida tuntakse eelkõige rinnastavate sidesõnadena: 1) eraldav või, 2) ühendav ja, 3) vastandav aga koos selle lühema variandina käsitatud partikliga $a$. Rinnastava sidesõna koht on ühendatavate moodustajate (lausete või lauseosade) vahel. Nagu ilmneb eeltoodud näidetest, leidub ka kasutusjuhte, kus siduv sõna on jäänud ühte lausesse, paikneb selle alguses või lõpus ja toimib pigem partiklina, mis ei seosta lausemoodustajaid, vaid viitab ebamäärasemale seosele eelneva või võimaliku järgneva tekstiga ja täidab vahel muidki ülesandeid. Nagu elavas keeles ikka, esineb ka vaadeldavate partiklite tegelikus kasutuses üleminekujuhte ja mitmefunktsioonilisust.

Vaatleme nimetatud rinnastavate sõnade toimimist väit- ja küsilausete perifeerias, otsides vastuseid järgmistele küsimustele.

- Mis funktsioone kannavad rinnastava lähtetähendusega sõnad vasakus ja paremas perifeerias?

- Kas keelematerjal näitab nihkeid tähenduses (funktsioonide vahel) ja positsioonis (eri perifeeriate vahel)?

- Kuivõrd sümmeetriline või asümmeetriline on eesti lause oma perifeeriate ja nende funktsioonide suhtes?

Analüüs on kvalitatiivne ja põhineb Tartu Ülikooli korpustel. Kasutust tänapäeva eesti keeles ja selle võimalikke ajalisi muutumisi vaatleme XX sajandi läbilõikekorpuse ilukirjandustekstide põhjal, kuivõrd ilukirjandusest, mis sünteesib allkeeli (Hennoste, Pajusalu 2013: 133), on oodata kasutusjuhtude suuremat mitmekesisust ning rohkem (inter)subjektiivsust. Lisaks on vajadust mööda vaadatud uuemat kasutust ka XXI sajandi materjalist - kuivõrd praeguse aja ilukirjandustekste korpuses pole, siis on materjali otsitud ajakirjanduse ja uue meedia tekstidest. Varasemate arengujoonte kohta oleme otsinud andmeid XVI-XIX sajandi kirjakeele korpusest. Kasutame niisiis kirjaliku keele materjale, kus lausete piirid on markeeritud ja perifeeriad eristuvad seega selgemalt kui kõneldud keeles. Kõrvutuseks vaatleme ka murdeandmeid Eesti murrete korpuse põhjal, püüdes leida selgete lausepiiridega juhte. Tänapäeva kasutuse iseloomustamiseks toetume lisaallikatena ka eesti keele seletavale sõnaraamatule ja enda keelepädevusele ${ }^{4}$. Partikli eristamisel konjunktsioonist

${ }^{4}$ Intuitsiooni kasutamist käsitame empiirilise keeleuurimise loomuliku osana: „Intuitsioonipõhist uurimistööd võib teha ilma muud tüüpi uurimiseta, kuid mitte vastupidi. Eriti korpusuuring eeldab tervet hulka intuitsioonipõhiseid ehk eelempiirilisi lahendusi." (Itkonen, Pajunen 2010: 73) 
on keskseks struktuuritunnuseks sõna esinemine muus funktsioonis kui lausemoodustajate seose väljendajana, kirjutatud teksti puhul on toetavaks vormitunnuseks sõna paiknemine ortograafiliselt vormistatud lause alguses või lõpus. Eeldame, et kirjutaja markeerib sellega otsese rinnastusseose puudumist.

\section{Koordinatiivsed partiklid}

\subsection{Partikkel või}

Sidesõnana vormistab või eraldavat rinnastust, selle põhitähendus on disjunktiivne, nt Eksam on kolmapäeval või neljapäeval; Stuudiumi lõpetamiseks kirjutate lõputöö või teete lõpueksamid. Sõna või abil pakutav alternatiiv võib peale erineva sisulise variandi olla ka lihtsalt eelneva variandi eitamine: Kas sa tuled võ i ei tule?

Vasakus perifeerias kasutatakse partiklit või tänapäeva keeles kõigis kolmes funktsioonirühmas. Teksti organiseerimiseks võib lausealguline või märkida alternatiivi pakkumist eelnevale kontekstile (9). Eesti keele seletav sõnaraamat toob välja partikli või parandava funktsiooni tähenduses 'see tähendab, täpsemalt, pigem ei'. (10)

(9) „Oome tuleb tagasi.” „Või saadab vanaisa” .. (ILU 1990)

(10) Kes on mõrvar? Või õigemini, kas üks teatud isik on süüdi mõrvas või mitte. (EKSS)

Puhtalt seostavad kasutused on tänapäeva keele materjalis harvad, enamasti väljendab lausealguline võ $i$ võimaliku alternatiivi pakkumise kaudu subjektiivseid ja intersubjektiivseid tähendusi. Subjektiivseteks tähendusteks on näiteks oletused, konstateeringud (11), kahtlus (12), imestus (13), üleolek (14), iseendale suunatud küsimus (15).

(11) Kui nad tallu jõudsid, hõikas mees oma ema õue ning rääkis ära, kuidas lood on. „Või asjad niikaugel.” (ILU 1980)

(12) Või need talupojale kunagi head on soovinud! (EKSS)

(13) Või nii, või tema sõidab välismaale! (EKSS)

(14) Või sa ise targem oled. (EKSS) 
(15) Võibolla istuksin just praegu laboris ning teeksin mõnda katset - mulle meeldis õhtuti töötada, kui inimesi vähem oli. Või vedeleksin hoopis kodus? (ILU 1990)

Intersubjektiivsed on näiteks etteheide (16), vastuvaidlemine (17), direktiivsus (18), kinnituse (19) või soovituse (20) küsimine, kahtlev küsimus (21). Intersubjektiivsete tähendustega kaasnevad enamasti ka subjektiivsed (näiteks modaalsed ja emotiivsed) nüansid. Mittesubjektiivne, teksti seostav tähendus kaldub seejuures tagaplaanile jääma.

(16) „Miks sa siis sellest sõna ei jätnud? Või oleksid helistanud.” (ILU 1980)

(17) „Pole minu asi valvata, mis kratid siia vilja tassivad,” kostab ta huupisõnu. „Või mina siin ainuke suksutaja olen?” (ILU 1990)

(18) „Sina ei tohi mind lüüa!” hüüdis Ella. „Või sa julged mulle vastu rääkida." (ILU 1900)

(19) Või on eksam hoopis ülehomme?

(20) Või ma ootan su ära?

(21) „Aga mina olin kolm nädalat haige!” hõiskas Jaagup. Edmund mõõtis teda oma kõõrdsilmaga: „Või nii?” (ILU 1990)

Lausestruktuuridest esineb peale täieliku lause ka kinnistunud struktuuriga fraaslauseid, nagu Või õigemini, Või ei, Või nii $(10,13,21)$.

Miks käsitame partiklit või lausetes nagu (20) ja (21), allpool ka partiklit ja lausetes nagu (38), partiklit aga lausetes nagu (51) küsimarkerina? Koordinatsioon on eesti keeles üks pidevalt toimivaid küsimarkerite allikaid. Nii tõlgendatakse eelneva kontekstiga seotud väide ümber oletuseks eelnevaga seostuva väite kohta ja sellest edasi info ebapiisavust väljendavaks küsimuseks, millega kaasneb lausealgulise seosemarkeri reanalüüs küsimarkeriks. Rinnastusmarkerid on küsimarkerite kasvulava, kust mõni partikkel on juba grammatiseerunud täiesti omaette grammatikaüksuseks ( $k a s$ ja $e g a$ ), ülejäänud aga püsivad valmiduses küsimust vormistada ja miks mitte ka kunagi küsipartikliks kujuneda. (Lähemalt vt Metslang jt ilmumas.)

Vana kirjakeele materjalis on seostavad kasutused ülekaalus kuni XVIII sajandini, mil vähehaaval lisandub intersubjektiivseid kasutusi (22). Küsiv või ilmub ilukirjandustekstidesse XVIII sajandil. XIX sajandi tekstides on juba esiplaanil küsimustega seotud intersubjektiivsed kasutusjuhud, millega sageli kaasneb emotiivsus $(23,24)$. 
(22) Woi mötlete teie Kirja asjata ütlewa: (meie) Waim/ ke meie sees ellab/ himmustab Kaddedust. (VAKK, 1715-UT, Jk. 4:5)

(23) Woi kas meie söbrus siis peaks lopma? küssis teine jälle. (VAKK, 1817Holtz, 143)

(24) Se töusis toli pealt ülles, astus Peetri pole ja ütles lahkeste: „Woi sinna se olled mo armas lapsoke?" (VAKK, 1843-Schüdlöffel, 919)

Paremas perifeerias esineb või tekstiorganiseerimise funktsioonirühmas laiendust markeerivana, näidates alternatiivide loendi avatuks jätmist (25).

(25) Aga ega sellel kõigel ei olnud siis mingisugust tähtsust. Hõbedal või riietel või... (ILU 1990)

Esineb ka subjektiivseid kasutusi, nt oletust (26) ja laiendamisega kaasnevat kahtlust (27). Intersubjektiivsuse suunas viivaks arenguks on XX sajandil levima hakanud kasutus küsimarkerina (28). Või (vä) paremas perifeerias on grammatiseerumas küsipartikliks, millega taotletakse kinnitust partiklit sisaldava lause sisule. Nihe põhineb teksti jätkamise funktsioonil, milleks on sama lause sisule alternatiivide pakkumine, parandused (vt Lindström 2001). Subjektiivsed kasutused põimuvad siingi intersubjektiivsetega, ka küsimus võib olla suunatud küsijale endale, et vastates teksti jätkata (29).

(26) „Sina pole teda ju näinud viiskümmend viis aastat.”

„Noh, siis on see nagu unenägu, mis äkki tõeks saab või... nagu see printsess, kes surmaunest üles äratatakse.” (ILU 1980)

(27) Aitüma, aitüma!

Mis sest söögist enam või... hoopis teised mõtted .. (ILU 1980)

(28) „Kuule, Sinead, sinuga on midagi juhtunud. Armunud oled või? Kas totter sädelus mu silmis on tõesti kõigile näha?" (ILU 1990)

(29) Siin näib mõni nägu isegi tuttavana. Olen ma neid inimesi tõesti kusagil näinud või... põrgusse. Võib-olla olengi, suur see linnake siis ära ei ole. (ILU 1990)

Vana kirjakeele tekstid ei paku näiteid partikli või kasutamise kohta paremas perifeerias. Ka murretes on see piiratud. Esimesest funktsioonirühmast leidub näiteid laiendava ümberformuleeringu (30) ja tagasihaarava kasutuse kohta (31). 
(30) Nääd ei lähä `senna `sisse või (...) aga `mette i ole räemette (TÕS)

(31) või miss Endrik oli vist või (KHN)

Ennekõike leiab näiteid partikli või kasutamise kohta murretes küsivas funktsioonis, kus ta kaasneb sageli lause alguses oleva partikliga kas (32), (33). Küsivas lauses võib väljenduda ka kahtlev väide (34).

(32) kas ütlen nime kaa või (...) (HLJ)

(33) kass kivi oli vähä ’jälle või (...) ja ku paelu läks siis (TÕS)

(34) aga kas see oli naa või (...) aga seda tää ’rääkis küll (TÕS)

Partiklil või on niisiis mitmekesist kasutust, eriti vasakus perifeerias. Varasemate sajandite materjal näitab nihete algamist tekstiorganiseerimisfunktsioonidest ja jätkumist subjektiivsetesse ja intersubjektiivsetesse funktsioonidesse. XX-XXI sajandi materjalis on kõik kolm funktsioonirühma esindatud. Küsipartiklina kasutamine algas vanas kirjakeeles vasakus perifeerias XVIII sajandil, parema perifeeria küsiva või $\sim v \ddot{a}$ arengut saab jälgida alates XIX sajandi lõpust.

\subsection{Partikkel ja}

Sidesõnana vormistab ja üldist, markeerimata ühendavat (konjunktiivset) seost, mis võimaldab üksteisele lisada lauseid või samalaadseid moodustajaid ilma nendevahelist seost täpsustamata: On jaanuarikuu ja õues on hanged; On jaanuarikuu ja muru haljendab; Vaasis on lilled, lehed ja oksad; Ta on väike ja tubli. Ühendaval seosel põhinevad ka edasised funktsioonid partiklina. Vasakus perifeerias pakub ja jätku eelnevale kontekstile (35).

(35) Siin naeratas temale tõesti õnn wastu - noore, ilußa, rikka leße näol. Ja Hans haaras õnneßt kinni. (ILU 1900)

Neutraalsele, teksti organiseerimisega seotud jätkamisele lisaks leidub ka (inter)subjektiivset kasutust: vastandava tähendusnüansiga vaidlemist, pahandavat kommenteerimist (36).

(36) „Onu juures käisin” wastas sulane ninakalt. „,Ja alles öö peale tuleb koju!” „Ei saanud ennemalt.” (ILU 1900)

Kontekstile jätku pakkumisest on välja kasvanud partikli ja kasutus küsimuse alustajana: nii küsilausele eelnevana (37) kui ka ainsa küsimarkerina 
(38). Ühendava seose tähendus võib seejuures olla tagaplaanil, pigem on ja lihtsalt lausungi alustaja. Küsimus võib olla suunatud ka kõnelejale endale kõneteema sissejuhatamiseks (39).

(37) „Antud juhul oli meil tarvis otsusele jõuda selles, mida kalad õnneks peavad."

„Ja kuidas sa nad siis rääkima paneksid?” (ILU 1970)

(38) „Ei kedagi: tõin lehed kodu ßääl nad nüüd on - tarwis aga laußet lugeda mis nõid õpetas ja raha ongi käes."

„Ja lehed lähewad rahaks?”

„Rahaks jah!” (ILU 1900)

(39) Rõõm teab veel sedagi, et vellel on alal see kümnekopikaline hõberaha, mille ta sai kaheksa-aastase poisikesena kirikhärralt. Oi, Rõõm tunneb Risti ja sellepärast jätkab ta oma juttu järgmiselt: „,Ja kas sa siin kandikohakesel õige kergelt kopikat näed? Ei siin rublad robinal rohkene ega kopik kergelt karmanni korju!"' (ILU 1930)

Paremas perifeerias kasutatud ja väljendab ennekõike intersubjektiivset laiendust, realiseerumata võimalust midagi lisada, pakkudes juurdemõtlemise võimalust ka kaasvestlejale (40).

(40) Et nii ja nii, ma tulin ikka päris tõsise asja pärast ja... Et kuulsin nagu ääri-veeri mööda, et sa tahtvat naist võtta ja... Et mina ka nagu poissmees veel ja... et kuidas oleks?... (ILU 1930)

Laiendamise võimalusel põhinevad kaasvestlejale suunatud ettepanekud, info ja kinnituse küsimised $(41,42)$, teksti jätkamiseks endale suunatud küsimused (43).

(41) küljetiparkimine ja asi ants, tagasipööre äkki kah ja? Minu ARKi eksam nägi välja nii, et kohe autosse. (UM)

(42) „Noh, aga mis te siis tegite? Käisidki siis eile Keilas ja?” „No muidugi!” (ILU 1990)

(43) Nüüd, siin lagedas ümbruses vanade haigete õunapuude vahel seistes, mõtles mees, et nii saksa kui vene keeles on sõna väli alati militaarse maiguga. Feld ja????. Eesti keel proovis seda militaarsust küll üle võtta, aga see ei hakanud kõlama. (ILU 1990)

Vanema kirjakeele tekstides figureerib lausealguline ühendav ja tekstiliigi retoorilise eripära tõttu ka intersubjektiivsena tõlgendatav ja mõnevõrra 
erandlikult Georg Mülleri käsikirjalistes jutlustes (44). Üldiselt on XVII sajandi ja ka XVIII sajandi esimese poole tekstides ühendava seose märkimiseks kasutusel sidesõna ning. Ka XIX sajandi tekstid ei paku näiteid sõna ja esinemise kohta vasakus perifeerias.

(44) Ia, Mincksarnatzel kombel annab tæma meile se Nouw? (VAKK, 1602-Müller 7/8)

'Ja missugusel kombel annab ta meile nõu?'

Paremas perifeerias ja vana kirjakeele korpuse andmetel ei esine. Põhjuseks on ilmselt kõnekeelelähedasi dialooge sisaldavate ilukirjandusteoste vähene osakaal selle korpuseosa tekstivalikus.

Niisiis on $j a$ suhteliselt noor siduv sõna, mille laiem levik kirjakeele tekstides algas XVIII sajandil. Sellel leidub küll mõnevõrra kõigi funktsioonirühmade kasutusi, kuid ühendav funktsioon on enamasti taustal tajutav, olulisi tähendusnihkeid ei ole toimunud.

\subsection{Partikkel aga}

Sidesõnana vormistab aga vastandavat (adversatiivset) seost, mida käsitame ühendava seose markeeritud alltüübina, mis peale 'ja'-seose väljendab seda, et ühendatud lausete või moodustajate vahel on mingi sisuline kontrast või vastuolu: On jaanuarikuu, aga muru haljendab; Ta on väike, aga tubli. Aga kasutused partiklina põhinevad vastandaval seosel: ühendatavad üksused ei ole omavahel alternatiivsed nagu võ $i$ puhul, vaid ühtaegu tegelikud nagu ja puhul, kuid lisaks mingis suhtes erinevad või vasturääkivad. (EKG II: 215-218) Aga on üldine vastandav sidesõna. Sellega saab väljendada kahte tüüpi vastandust: kontrastiivset, mis lihtsalt kõrvutab erinevaid nähtusi, nt paremal on pood, aga vasakul pank; vrd (45), ja ootusvastast ehk möönvat vastandust, nt läksin leiba ostma, aga pood oli kinni, vrd (46) (Erelt 2010). Eri tüüpi vastanduste soodumus erinevateks partiklilisteks kasutusteks vajab edasist uurimist. Küsimarkerina toimiva aga puhul on ilmnenud, et mõni küsilausemall põhineb kontrastiivsel vastandusel (nt Aga tema?), mõni ootusvastasel vastandusel (näide 54 allpool) (Metslang jt ilmumas).

Vasakus perifeerias on partiklil aga mitu kasutust. Teksti organiseerimine lähtub vastandavast seosest eelneva tekstiga (46), seejuures võib vastandav tähendus jääda tagaplaanile, nii et aga märgib pigem teemapööret teksti jätkates $(45,47)$ või kõnevooru alustades $(48)$. 
(45) Feministisikä stuntmannid tegid head tööd. päris naturaalsed teised. Aga nüüd magama. Ommikul tuleb piimamees ja ajab mo päiksetõusuaegu ülesse ;))))))))) (UM)

(46) Ühel päeval jahilt tulles ütles ta mulle: „Meil oli täna hea jahiõnn ja saime palju saaki. Aga kõik viidi Annela mõisa rentniku poole. Temal on ülehomme sündimise päev ja tahab seda toredasti pühitseda." (ILU 1900)

(47) Kokku oli see kõik nii peadpööritav ja jube, ülalpool saalivad pilved ringi ning järjest rohkem tunned, kuidas sa tükkis torniga kõigud ning järgmisel silmapilgul võid luugist alla lennata. Aga siis ilmusid aidalakka Tohvri Raik ja Nuuma Sass ning tulid joonelt nende poole .. (ILU 1970)

(48) „Olen walmis härra käsku täitma,” rääkis Mihkel poolpõiki kumardades ja waatas altkulmu härra otßa. „Aga ma tahtßin härrale ka midagi rääkida!” „Noh?” „Aßi on halb!” „Kuidas halb?” „Rahwas streigib.” „Mis” kärgatas Jalakas wihaga. (ILU 1900)

Aga-laused väljendavad ka subjektiivseid ja intersubjektiivseid tähendusi: üllatust, etteheidet (näide 8 eespool), vastuvaidlemist, veenmist (49) jne.

(49) Aga praegu pole veel hilja teisiti otsustada. (ILU 1970)

Küsimuse alguses võib aga eelneda muul viisil markeeritud küsimusele, kuid olla ka ainsaks küsimarkeriks. Küsimus võib olla suunatud kaasvestlejale $(50,51)$ või ka iseendale teksti või arutluse jätkamiseks $(52)$. Samades funktsioonides nagu aga leidub vasakus perifeerias ka partiklit $a$, näiteks teksti jätkavana (53) või küsimust markeerivana (54).

(50) „wiinawoorimehed jah!” Aga kes? (ILU 1900)

(51) Aga sa ju armastad mind? (ILU 1990)

(52) Hirmus, halastamata meri. - Aga kuhu jõuda? Kott-pime ja kuigi ka wälk Bilmapilguks walgustab, pole muud näha, kui mäsßawaid wee kuhilaid. (ILU 1900)

(53) Sellest 151x25 näeb jah paremini kas on tegemist naise v6i mehega. A sa oskad päris hästi teha neid mehikesi. (UM)

(54) „Sa mind ei tahaks siia elama võtta?” - „A sul on ju mingi elamine?” (ILU 1990) 
Vana kirjakeele tekstides esinebki aga (varasemad kirjakujud aigkas, agkas) vaid vasakus perifeerias. Esimesed esinemisjuhud vasakus perifeerias on XVII sajandi esimese poole kiriklikes tekstides (Heinrich Stahlil), piiblitekstis on ühendav aga sage. Nii XVII sajandi kui ka XVIII sajandi esimese poole tekstides on selgelt esiplaanil eelneva tekstiga vastandavalt seostav funktsioon (55). Näiteid leidub siiski ka vastandusel põhinevate subjektiivsete tundeväljenduste (56) ning intersubjektiivsete pöördumiste (57) kohta, mis võib lähtuda kirikutekstide stiililisest eripärast. Alates XVIII sajandist, kui hakkab ilmuma rahvapäraseid dialooge ja jutte, lisanduvad retoorilistele küsimustele ka infoküsimused (58), kus esialgu esineb aga koos muu küsipartikliga, nt partikliga kas. XIX sajandi esimesel poolel ilmuvad ka aga kasutused iseseisva küsipartiklina (59). Leidub muidki intersubjektiivseid kasutusi: vastuvaidlemist (60), emfaatilist pöördumist (61). Nagu paralleeltekstidest näha, võib aga levik olla tuge saanud saksa sõna aber samalaadsetest partiklilistest kasutustest. Ka murretes esineb aga põhiliselt lausungi algul.

(55) Agkas paljo rahwas laotasit ommat rihdet te pehle..

Aber viel Volcks breitet die Kleider auff den Weg .. (VAKK, 1638Stahl, 2)

(56) Agkas minna lotan Jssand sünno pehl/

Aber ich harre/ HERR/ auff dich/ (VAKK,1638-Stahl, 6)

(57) Agkas minna ütlen teile: Paljo sahwat tullema sest hohmickust/ ninck sest öchtust ..

Aber ich sage euch/Viel werden kommen vom Morgen und vom Abend .. (VAKK, 1638-Stahl, 28)

(58) Agga kas ka Jummala sanna ligub teie jures?

Aber ist Gottes Wort auch in eurem Gesinde bei euch im Gange? (VAKK, 1732-Helle, 375)

(59) Agga se on ommeti minno pärralt? wastas laps (VAKK, 1807-Luce, 32)

(60) Agga se ep olle nenda. Kuule, ma tahan sulle sedda nenda selgeste ärra selletada .. (VAKK, 1782-Willmann, 38)

(61) Agga sinna rummal! Miks sa lassed ennast meelega petta? (VAKK, 1782-Willmann, 149) 
Paremas perifeerias väljendab aga (partiklit $a$ lause lõpus ei leidunud) vastandava jätkamise poolelijättu (62), mis omakorda võib märkida kõhklemist, viivitamist ning olla jätkamise vältijana viisakuse teenistuses (näide 6 eespool). (Viimast funktsiooni on täheldatud ka korea samatähendusliku partikli kuntey puhul $^{5}$.)

(62) Eeva elus ei olnud palju võimalusi. Raha ega perekonda tal polnud ja kõige parem, mida nii ta vaimu kui välimuse kohta öelda võis, oli, et tüdruk tõesti püüab ihust ja hingest, aga... Temast vaadati liiga sageli üle ning andekate, jõukate ja imetletute kaastunne või halvemal juhul kärsitus olid segatud hooletultvarjatud põlastusega. (ILU 1990)

Eripärane on kasutus käsu intensiivistajana (63).

(63) „Söö, taadike, söö aga!” rõõmustas Petrov. (ILU 1990)

Aga toimib küsivana nii lause alguses kui ka lõpus, kuid lauselõpuline küsiv aga (64) on enamasti pigem omaette rõhuga, edasisele kontekstile suunatud jätk (vaeglause) kui lausesse kuuluv partikkel. Lause lõpus esineb siiski ka rõhutut tagasihaarde-aga (65), mis ei haaku mitte järgneva, vaid varasema kontekstiga, vt allpool jaotis 3. Küsiva lause lõpus väljendab selline aga ka iseendale jututeema jätkamiseks suunatud küsimust (66).

(64) Ma ei tea? Äkki pole tema organism loodud suurte koormuste talumiseks. Lihased on tal suurepärased, aga? Teen ehk Jallaile liiga, aga võib-olla ta ei talu 600? (ÕL 2007)

(65) Riiklik õppelaenu määr on 25 000. -, kuid olen kuulnud, et on võimalik ka rohkem saada. Nimelt oleks vaja kuskil 45 000. - Kuidas aga? (UM)

(66) Vanasti viisakas kapten laevas (omaette jumal taevas), enne kui mehe tormiga masti saatis, luges vaikselt issameie, ütles aamenigi peale justkui kinnituseks, et tema omalt poolt on teinud kõik. Nüüd aga? Inimesi aetakse tapule ja hauda nagu seakarja. (ILU 1970)

Siiski on lauselõpuline aga eesti kirjakeeles pigem uus nähtus - vana kirjakeele tekstides seda tüüpi kasutusjuhte ei leidu ja ka murretes on selline kasutus harv. Murretest leidus üksikuid näiteid, enamasti eitavates lausetes, kus on tegemist (inter)subjektiivse vastanduse rõhutamisega $(67,68)$.

5 Sung-Ock Sohn, The emergence and function of the left peripheral versus the right peripheral expressions in Korean: from a discourse marker to a final particle. Ettekanne 13. rahvusvahelisel pragmaatikakonverentsil New Delhis 10. septembril 2013. 
(67) päris agana+' leiba küll ei tehtud aga (...) ohra+leib se oli (KOS, 3496)

(68) ega siis oleks midägi old aga (...) lükkas kõrvale (JÕE, 3606)

Nagu või, nii on ka aga sajandite vältel omandanud mitmesuguseid kõigi kolme funktsioonirühma kasutusi, eriti vasakus perifeerias. Levik paremas perifeerias ilmneb viimase sajandi materjalis. Aga puhul esineb märgatavaid tähendusnihkeid, nagu teemapööre või emfaatiline pöördumine vasakus perifeerias, käsu intensiivistamine paremas perifeerias. Leidub ka eripärast sõnajärjevõtet - tagasihaaret.

\section{Vasaku ja parema perifeeria kõrvutuseks}

\subsection{Koordinatiivsete partiklite funktsioonidest vasakus ja paremas perifeerias}

Vaadeldud partiklite peamised funktsioonid ja nende kujunemisteed on kokkuvõtlikult esitatud joonistel 2 ja 3. Vasakus perifeerias (joonis 2) on rinnastaval sidesõnal põhineva partikli esimeseks ülesandeks väljendada samalaadset rinnastavat seost laiemalt, eelneva kontekstiga seostatult.

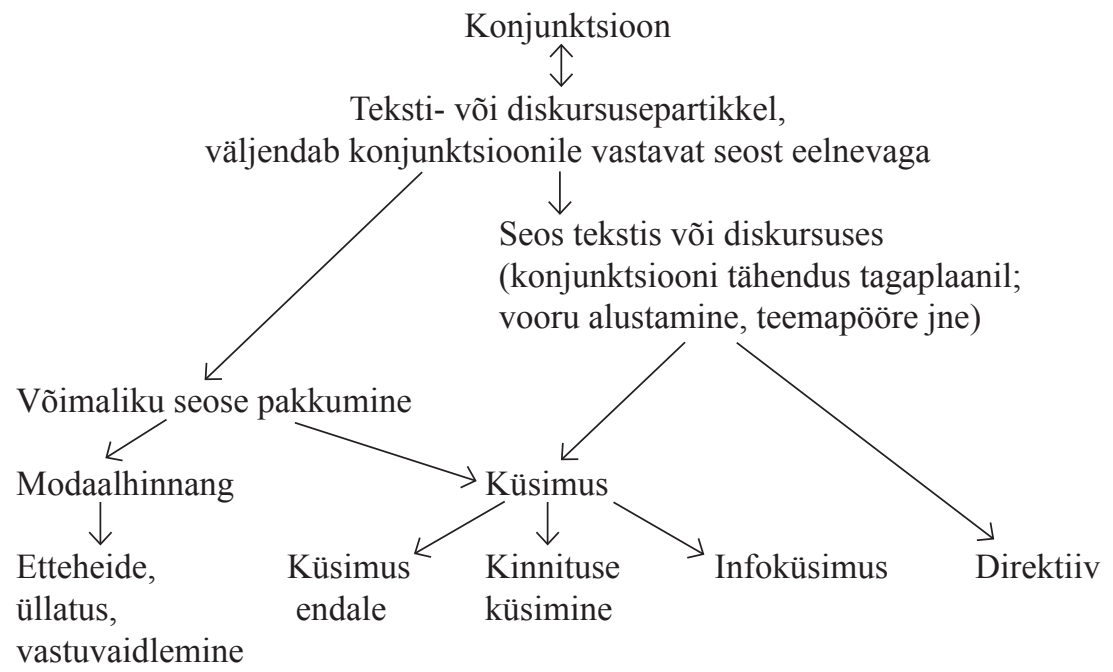

Joonis 2. Koordinatiivse partikli funktsioone vasakus perifeerias 
Sellel põhineb omakorda teemapöörde ja vooruvahetuse markeerimise funktsioon ning mingi võimaliku seose pakkumine - juurdemõeldava sisu lisamine, vastandamine või alternatiivile vihjamine. Võimaliku seostuva sisu oletamisest kasvab välja modaalhinnang, küsimus ja ka käsk või palve. Hinnang omakorda on aluseks etteheitele, üllatuse väljendamisele ja vastuvaidlemisele. Küsimus võib olla suunatud kaasvestlejale (küsitakse infot või kinnitust) või iseendale, et anda tekstile teema. Üldine suund on niisiis teksti organiseerimise funktsioonist subjektiivsusse ja sealt edasi intersubjektiivsusse, kuigi funktsioonid põimuvad ja näiteks küsimuse korral on intersubjektiivne, kuulajale suunatud küsimus arenguloogikalt varasem kui subjektiivne, endale suunatu.

Paremas perifeerias (joonis 3) on nihete üldine suundumus sama. Teksti organiseerimine, juhul kui moodustajatevaheline rinnastus puudub, seisneb potentsiaalsele lisandusele, vastandusele või alternatiivile vihjamises. Kui seostatavat üksust ei oletata, vaid lihtsalt markeeritakse selle olemasolu, on tegemist realiseerumata laiendusega, mida saab omakorda kasutada jätkamise katkestuse markeerimiseks, kõhkluse ja viivituse väljendamiseks. Selline potentsiaalne mittejätkamine võib olla ka viisakusvõte, ebameeldiva jätkamise vältimine. Teiselt poolt võib potentsiaalset jätku siiski oletada, oletusest aga omakorda kasvab välja küsimus oma alaliikidega.

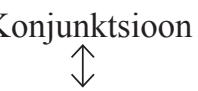

Teksti- või diskursusepartikkel, väljendab järgnevat konjunktsioonile vastavat potentsiaalset seost

Realiseerumata laiendus

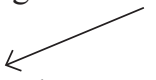

$\downarrow$

Kõhklus, viivitus, jätku sõnastamata jätmine<smiles></smiles>

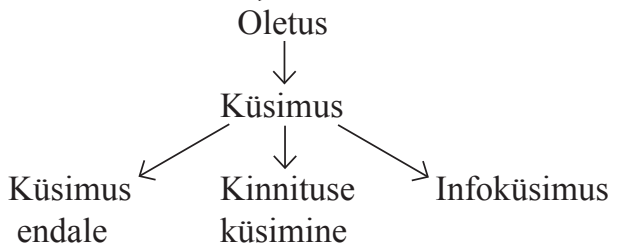

Joonis 3. Koordinatiivse partikli funktsioone paremas perifeerias

Niisiis ei ilmne ka eesti keeles vaadeldavate partiklite põhjal otsustades lause piiripositsioonide üksühest tööjaotust subjektiivsuse ja intersubjektiivsuse vahel, eesti lause on sümmeetriline. Peamine erinevus on 
esimeses, organiseerivas funktsioonis, millest muud kasutused on välja kasvanud. Vasak perifeeria pakub alternatiivi, kõrvutust, jätku, vastandust olemasoleva eelneva konteksti suhtes, parem perifeeria mõeldava järgneva konteksti suhtes. Edasised kasutusviisid vähendavad seda erinevust, eriti on märgata vasakul kujunenud kasutuse nihkumist paremasse perifeeriasse. Kõik vaadeldavad funktsiooninihked on XX-XXI sajandi materjalis olemas. Eri perioodide kirjakeele materjal näitab, et mõlemas perifeerias on funktsiooninihete järjekord samasugune: organiseerimine $>$ subjektiivsus $>$ intersubjektiivsus (vt Traugott 2003, 2012). Näiteks aga korral on üks nihkeahel selline: lausesisu vastandav seos eelneva konteksti suhtes $>$ oletus vastanduva propositsiooni tõesuse kohta $>$ üldküsimus vastanduva propositsiooni tõesuse kohta (vt ka Metslang jt ilmumas). Subjektiivsed ja intersubjektiivsed kasutused kujunevad ennekõike vasakus perifeerias, piiratumalt ja hiljem ka paremas perifeerias.

\subsection{Nihkeid vasakust perifeeriast paremasse}

Perifeeriatevahelise dünaamikana on märgata vasakus perifeerias kujunenud kasutuse nihkumist paremasse perifeeriasse. Siinse materjali põhjal oleme täheldanud kahte ülekandemehhanismi: mõlemasse perifeeriasse partiklit võimaldavat sildkonteksti ja tagasihaaret.

Mõlemat perifeeriat võimaldav sildkontekst on võinud toetada lauselõpulise küsipartikli või kujunemist. Või toimimine küsipartiklina algas kirjakeele korpuse andmeil XVIII sajandil, lauselõpuline küsipartikkel või (vä) hakkas kujunema aga alles XX sajandil (vt Metslang jt 2011). Küsiva funktsiooni paremasse perifeeriasse levimist toetavateks sildkontekstideks on juhud, kui küsiv või sobiks nii lause algusse kui ka lõppu (69), vrd (70) ja eespool (31).

(69) Mul oli ka aastaid ebamugav Kultuurkapitalilt raha võtta (mitu korda öeldi - Peeter, miks sa avaldust ei kirjuta, raha ei taha või? (ILU 1990)

(70) Mul oli ka aastaid ebamugav Kultuurkapitalilt raha võtta (mitu korda öeldi - Peeter, miks sa avaldust ei kirjuta, või ei taha raha?

Tagasihaarde kaudu (vt joonis 1 eespool) on levimas lauselõpuline aga eelneva tekstiga seostavas ja lisaks ka küsivas funktsioonis (eespool näited 4 ja 65). 
Tagasihaaret inglise kõnekeeles on vaadelnud Alexander Haselow (2011, 2012). Haselow (2012: 3609-3610) selgitab partikli then 'siis' positsiooni nihkumist: eelmise lause või repliigiga seostuv then paikneb algselt vasakus perifeerias (71), kuid võib kanduda ka paremasse (72) - lause lõpp on viimane võimalus näidata seost kaugemale vasakule, eelmise lause või repliigiga.

(71) go and ask Toni where it is

then you can (.) ask her and see if she's suitable

'Mine ja küsi Tonilt, kus see on. Siis sa võid temalt küsida ja vaadata, kas ta on sobiv.'

(72) oh he's fairly happy (.)

uhm (.)

why do (-) why do you think he doesn't write then

'Oh, ta on üsna õnnelik. Hmm, Miks sa - miks sa siis arvad, et ta ei kirjuta.'

Partikli but 'aga' tagasihaardekasutust, mis võtab partikli however 'siiski, ometi' koha ja funktsiooni, on täheldanud Kate Beeching (2009: 97).

(73) A: Real Madrid are playing tonight

B: They're not televising it but.

'Madridi Real mängib täna õhtul. - Nad ei kanna seda aga üle.'

Tagasihaarde-aga esineb tavaliselt fragmentaarsetes lausetes, kus aga ees on ainult üks-kaks fraasi (eespool näited 4 ja 65). Selline kasutus on sildkontekst, mis põhineb aga lausesisesel kasutusel tüüpiliselt teisel kohal (nn Wackernageli positsioonis) (74). Uue meedia materjal näitab, et rõhutuna häälduv tagasihaarde-aga on nüüdisajal levimas ka terviklikele lausetele $(75,76)$.

(74) Taevased puhtad hääled tungisivad, kui armsad muusika helid, nende südametesse ja tõivad neile rahu. Varsti aga ilmus kiusaja nende sekka. (ILU 1900)

(75) 19 ei tundu eriti objektipilt, rohkem lihtsalt mingi masin tänaval. võibolla rohkem keskkonda ümberringi vaja, praegu minu jaoks ei tööta. see tume maja sein vasakul meeldib aga! (UM)

(76) Ashley: jessicaz_eml yoyo ! =DDD caupz: Liisa kuda muidu läheb aga? Liisa: aga caupz muidu läheb. (UM) 
Kõrvalepõikena vaatame, millist huvitavat arengut tagasihaarde suunas on läbimas nüüdiskeeles proadverb kusjuures. Selle lähtefunktsiooniks on sidendina toimiv proadverb, mis alistab kogu lause juurde kuuluvat kõrvallauset (EKG II: 315) - niisiis on see alistusseos ebatüüpiline ja osalauseid kui tervikuid ühendavana lähedane rinnastusele. Nii pole ka põimlausel (77) erilist tähenduserinevust rindlausega (78) võrreldes.

(77) Ta sammub piki randa edasi, kusjuures kerge meretuul saadab teda. (ILU 1930)

(78) Ta sammub piki randa edasi ja teda saadab kerge meretuul.

Nõnda on kusjuures hakanud käituma ka rinnastavat seost eelnevasse konteksti projitseeriva konnektiivpartiklina. Kuivõrd tegemist on kõrvallauset ühendava sidendiga, siis ühtlasi on toimunud ka insubordinatsioon, kõrvallause iseseisvumine. Uue meedia korpusest leidub näiteid sõna kusjuures kasutuse kohta vasakus perifeerias ja ka selle tagasihaardekasutusest paremas perifeerias $(79,80)$.

(79) Kas sa oled mind unustanud? : p Võid ju küsida alati :) - Hmüh .. kusjuures olin tõesti unustanud (UM)

(80) Ma pole isiklikult kohanud ei selliseid töid ega selliseid mehi, elan ka ära (ja mitte halvasti kusjuures) : P (UM)

Toimuvad nihked järjestuvad niisiis järgmiselt: proadverb, alistav sidend > proadverb, rinnastav sidend $>$ LP konnektiivpartikkel $>$ RP konnektiivpartikkel (tagasihaare, teksti organiseerimise funktsioon). Analoogilisi arenguid sellise ahela üksikute etappide kohta muudes keeltes on näiteks jaapani põhjussidesõna kara nihe konnektiivpartikliks (Higashiizumi 2011) ning eelkirjeldatud partiklite then ja but, samuti norra altså 'niisiis', nemlig 'nimelt' puhul (Vaskó, Fretheim 1997) täheldatud nihked tagasihaardena vasakust perifeeriast paremasse.

Jaapani keeles toimuva arenguga kõrvutades hakkab silma, et seal paikneb kõrvallause sidend erinevalt eesti keelest kõrvallause lõpus, niisiis iseseisvunud kõrvallause partiklina leiab ta end paremast perifeeriast (Higashiizumi 2011), mitte vasakust nagu eesti keele jt Euroopa keelte sidenditest kujunevad partiklid. Sidendi positsioonis ja seotuses eelneva või järgneva osalausega võib peituda üks perifeeria valikut mõjutav tegur. Eesti keeles, nagu ilmselt teisteski Euroopa keeltes, on alistussidend kõrvallause alguses, ja ka rinnastav sidend on tihedas seoses järgneva 
rindliikmega - Euroopa keeltele omane rinnastuse tüüp on $A$ and- $B$. Kui sidend hakkab toimima partiklina, toimub see seetõttu ennekõike lause vasakus perifeerias, selle kõrval eelkirjeldatud asjaoludel ka paremas (samamoodi näiteks ka soome alistussidend että, Koivisto jt 2011). Aasias on levinud rinnastuse mallid $A$-and $B$ ning $A$-and $B$-and, kus rinnastuse marker seostub eelneva rindliikmega (Stassen 2000; Haspelmath 2001: 1502). Sel moel esineb nii kõrvallauses kui ka rinnastatud osalauses seose markerit paremas perifeerias - see on üks allikas partiklite paiknemisele paremas perifeerias. Parema perifeeria kesksuses on omakorda nähtud Aasia keelte areaalset tendentsi (Traugott 2012; K. Izutsu, M. N. Izutsu' $)$.

\section{Kokkuvõtteks}

Nii tänapäeva eesti keele, vana kirjakeele kui ka murrete materjalist ilmneb, et eesti lause on perifeeriate suhtes pigem sümmeetriline, mõlemas perifeerias on esindatud kõik kolm funktsioonirühma: teksti organiseerimine, subjektiivsus, intersubjektiivsus. Peamine erinevus on esimese, teksti või vestlust organiseeriva funktsiooni sisus: vasak perifeeria pakub alternatiivi, kõrvutust, jätku, vastandust olemasoleva eelneva konteksti suhtes, parem perifeeria mõeldava edasise konteksti suhtes. Neist seostest kasvavad välja subjektiivsed kasutused (nt seoste oletamised ja neile hinnangu andmised) ja sealt edasi intersubjektiivsed kasutused (oletusest tuleneb küsimus, hinnangust etteheide jne), ja küsivast kasutusest järgneb omakorda subjektiivne küsimus iseendale. XX-XXI sajandi keeles on kõik need funktsioonid esindatud ja põimunud, kirjakeele ajaloo põhjal on näha nihet esimesest kolmanda funktsioonirühma suunas. Vaadeldud koordinatiivsed partiklid on tugevamalt esindatud vasakus perifeerias; esineb nihkeid vasakust perifeeriast paremasse. Selliste nihete mehhanismideks on peamiselt sildkontekstid ja viimasel ajal mõne partikli puhul ilmnenud tagasihaare.

Eesti keele ja ka mõne muu Euroopa keele partiklite levimine vasakust perifeeriast paremasse on vastupidine tendents võrreldes näiteks jaapani ja

${ }^{6}$ Katsunobo Izutsu, Mitsuko Narita Izutsu, Fixation at Right and Left Peripheries. Ettekanne 13. rahvusvahelisel pragmaatikakonverentsil New Delhis 12. septembril 2013. 
korea keelele omase partikli kujunemisega vasakus perifeerias ja levimisega paremasse. Niisiis on keeled oma perifeeriate tendentsidelt erinevad ja selles on oma roll lausepartiklite üldisel paiknemisel ning sidenditest kujunevate partiklite korral ka liitlause ehitusel ja sidendite positsioonidel osalausete suhtes. Eesti partiklite puhul täheldatud tendentsis tõsta esile vasakut perifeeriat võib oletada areaalset ilmingut, sest lausealgulised partiklid on omased Läänemere areaali keeltele, erinedes näiteks parema perifeeria kesksetest Aasia keeltest.

\section{Lühendid}

EE - Eesti Ekspress, HLJ - Haljala, ILU - ilukirjandustekstid, JÕE - Jõelähtme, KHN - Kihnu, KOS - Kose, TÕS - Tõstamaa, UM - uus meedia, VAKK - vana kirjakeele korpus, ÕL - Õhtuleht

\section{Kirjandus}

Beeching, Kate 2009. Procatalepsis and the etymology of hedging and boosting particles. - Current Trends in Diachronic Semantics and Pragmatics. Ed. Maj-Britt Mosegaard Hansen, Jacqueline Visconti. Bingley: Emerald, 81-106.

EKG II = Mati Erelt, Reet Kasik, Helle Metslang, Henno Rajandi, Kristiina Ross, Henn Saari, Kaja Tael, Silvi Vare 1993. Eesti keele grammatika. II. Süntaks. Lisa: Kiri. Peatoim. Mati Erelt, toim. Tiiu Erelt, Henn Saari, Ülle Viks. Eesti Teaduste Akadeemia Keele ja Kirjanduse Instituut. Tallinn.

EKSS $=$ Eesti keele seletav sõnaraamat. 1-6, 2009. „Eesti kirjakeele seletussõnaraamatu" 2., täiendatud ja parandatud trükk. Toim. Margit Langemets, Mai Tiits, Tiia Valdre, Leidi Veskis, Ülle Viks, Piret Voll. Eesti Keele Instituut. Tallinn: Eesti Keele Sihtasutus. http://www.eki.ee/ dict/ekss/index.cgi (02.02.2014).

Erelt, Mati 2010. Vastandavatest sidesõnadest eesti keeles. - Keele rajad. Pühendusteos Helle Metslangi 60. sünnipäevaks. (= Eesti ja soome-ugri keeleteaduse ajakiri 1-2.) Tartu, 55-68.

Haselow, Alexander 2011. Discourse marker and modal particle: the functions of utterance-final then in spoken English. - Journal of Pragmatics 43 (14), 3603-3623.

Haselow, Alexander 2012. Subjectivity, intersubjectivity and the negotiation of common ground in spoken discourse: final particles in English. - Language \& Communication 32 (3), 182-204. 
Haspelmath, Martin 2001. The European linguistic area: standard average European. - Language Typology and Language Universals. An International Handbook. Vol. 2. Ed. Martin Haspelmath, Ekkehard König, Wulf Oesterreicher, Wolfgang Raible. (= Handbücher zur Sprach- und Kommunikationswissenschaft 20.2.) New York: Walter de Gruyter, $1492-1510$.

Hennoste, Tiit, Karl Pajusalu 2013. Eesti keele allkeeled. Õpik gümnaasiumile. Tallinn: Eesti Keele Sihtasutus.

Higashiizumi, Yuko 2011. Are kara 'because'-clauses subordinate clauses in present-day Japanese? - Subordination in Conversation. A CrossLinguistic Perspective. Ed. Ritva Laury, Ryoko Suzuki. Amsterdam: John Benjamins, 191-205.

Itkonen, Esa, Anneli Pajunen 2010. Empiirisen kielitieteen metodologiaa. (= Suomi 199.) Helsinki: Suomalaisen Kirjallisuuden Seura.

Koivisto jt 2011 = Aino Koivisto, Ritva Laury, Eva-Leena Seppänen. Syntactic and actional characteristics of Finnish että-clauses. - Subordination in Conversation. A Cross-Linguistic Perspective. Ed. Ritva Laury, Ryoko Suzuki. Amsterdam: John Benjamins, 69-102.

Lindström, Liina 2001. Grammaticalization of või/vä questions in Estonian. Papers in Estonian Cognitive Linguistics. Ed. Ilona Tragel. (= Publications of the Department of General Linguistics 2.) Tartu, 90-118.

Metslang jt 2011 = Helle Metslang, Külli Habicht, Karl Pajusalu. Developmental paths of interrogative particles: the case of Estonian. - Folia Linguistica Historica 45 (32), 149-187. http://dx.doi.org/10.1515/flih.2011.006.

Metslang jt ilmumas $=$ Helle Metslang, Karl Pajusalu, Külli Habicht. Conjunctive markers of polar questions in Estonian. - New Trends in Nordic and General Linguistics. Linguae et Litterae. Berlin: DeGruyter Mouton.

Stassen, Leon 2000. AND-languages and wITH-languages. - Linguistic Typology 4.1, 1-54. ww.uio.no/studier/emner/hf/ikos/EXFAC03-AAS/h05/ larestoff/linguistics/Chapter\%204.(H05).pdf. http://dx.doi.org/10.1515/ lity.2000.4.1.1.

Traugott, Elizabeth Closs 2003. From subjectification to intersubjectification. - Motives for Language Change. Ed. Raymond Hickey. Cambridge: Cambridge University Press, 124-139.

Traugott, Elizabeth Closs 2012. Intersubjectification and clause periphery. English Text Construction 5 (1). Special Issue. Intersections of Intersubjectivity. Ed. Lieselotte Brems, Lobke Ghesquière, Freek Van de Velde. Amsterdam: John Benjamins, 7-28. http://dx.doi.org/10.1075/ etc.5.1.02trau.

Valdmets, Annika, Külli Habicht 2013. Episteemilistest modaalpartiklitest eesti kirjakeeles. - Teoreetilisest keeleteadusest Eestis III. (= Eesti ja soomeugri keeleteaduse ajakiri 4-1.) Tartu, 205-222. 
Vaskó, Ildikó, Thorstein Fretheim 1997. Some central pragmatic functions of the Norwegian particles altså and nemlig. - Modality in Germanic Languages. Historical and Comparative Perspectives. Ed. Toril Swan, Olaf Jansen Westvik. Berlin: Walter de Gruyter, 259-291.

\section{Korpused}

Eesti keele koondkorpus. http://www.cl.ut.ee/korpused/segakorpus/ (09.02.2014). Eesti kirjakeele korpus 1890-1990. http://www.cl.ut.ee/korpused/baaskorpus/ index.php?lang=et (09.02.2014).

Eesti murrete korpus. http://www.murre.ut.ee/murdekorpus/ (09.02.2014).

Vana kirjakeele korpus. http://www.murre.ut.ee/vakkur/Korpused/korpused.htm (09.02.2014).

Helle Metslang eesti ja üldkeeleteaduse instituut Tartu Ülikool

Jakobi 2

51014 Tartu

metslang@ut.ee

Karl Pajusalu

eesti ja üldkeeleteaduse instituut

Tartu Ülikool

Jakobi 2

51014 Tartu

karl.pajusalu@ut.ee

Külli Habicht

eesti ja üldkeeleteaduse instituut

Tartu Ülikool

Jakobi 2

51014 Tartu

kulli.habicht@ut.ee 


\title{
Coordinative particles in the sentence periphery
}

\author{
Helle Metslang, \\ Karl Pajusalu, Külli Habicht
}

Sentence content is often connected to context, the speaker's assessments and the speech situation through elements located in the sentence periphery. Examining the Estonian particles või, ja, and aga, all of which have developed from coordinating conjunctions, the article aims to determine the following: 1) how symmetrical/asymmetrical Estonian sentences are; 2) which functions these particles perform in the left periphery (LP) and which in the right periphery (RP); whether the language data indicate shifts in meaning (from one function to another) and position (from one periphery to the other). The analysis is based on the language corpora of the University of Tartu.

We distinguish the following functions: 1) text/discourse organization: drawing connections with the preceding or following text; 2) subjectivization, 3 ) intersubjectivization. Both the standard language and dialect show a symmetrical distribution of these functions, as all three are represented in both the LP and the RP. Subjective and intersubjective uses are found primarily in the LP, to a more limited extent in the RP; on both peripheries, the order of function shifts follows the scale nonsubjective $>$ subjective $>$ intersubjective. We also observe that uses established in the LP sometimes move to the RP, primarily through the mechanisms of afterthought and bridge contexts. The prominence of the left periphery in Estonian may reflect an areal phenomenon, since sentence-initial particles are common in the Circum-Baltic languages, unlike for example the RP-heavy Asian languages.

Keywords: subjectivization, intersubjectivization, interrogative particle, afterthought, Estonian 